\title{
A single-centre audit of junior doctors' diagnostic activity in medical admissions
}

\author{
S Bhandari \\ Consultant Nephrologist and Physician/Honorary Clinical Reader, Department of Renal Medicine, Hull and East Yorkshire Hospitals NHS \\ Trust and Hull York Medical School, Kingston upon Hull, UK
}

\begin{abstract}
Practising doctors are distinguished from other healthcare staff by their role in making a clinical diagnosis. Huge changes in training and working practice in the past 15 years may have left many junior doctors ill equipped or preferring not to synthesise information to conclude a clerking with a diagnosis or differential diagnosis. This report details a retrospective study of acute medical admissions (AMU) first seen in the emergency department (A\&E) and the diagnostic activity of junior doctors in both settings. The documented diagnostic conclusion and reported differential diagnosis was compared with that of the relevant admission consultant. The aim was to see if doctors completed their clinical assessment by establishing a 'reasonable differential diagnosis' or simply used the presenting complaint (a symptom) of the patient as the 'diagnosis'.
\end{abstract}

One hundred patients' records (66 male and 34 female of mean age 57.4 years [20-94 years]) were studied. The majority of cases came from the cardiac and neurology domains of diagnosis. A total of $53 \%$ of cases seen in A\&E by clinicians were given a clinical 'symptom' as a final diagnosis or differential diagnosis. A further $18 \%$ referred to the wrong clinical domain in their assessment, and $22 \%$ of cases were concordant with the eventual consultant diagnosis. In the AMU $20 \%$ of cases were given a symptom as a final diagnosis and $11 \%$ the wrong domain; $45 \%$ of diagnoses were concordant. The grade of the doctor, from foundation year (FYI) to specialty registrar (ST3), led to an expected improvement in the assessment and documentation of a possible diagnosis rather than a symptom for both A\&E and AMU settings. In summary, junior doctors did not routinely document a clinical diagnosis or differential diagnosis at the conclusion of their clerking, regardless of experience. The reasons for this deferred activity are considered.

KEYWORDS Clinical reasoning, diagnosis, doctor, grade, symptom

DECLARATION OF INTERESTS Dr Bhandari has received honoraria for lectures and funding to attend conferences from Amgen, Roche, Astellas, BMS, Novartis and Pfizer. No external or internal funding was used to carry out this study.
Published online December 2009

Correspondence to S Bhandari, Hull and East Yorkshire Hospitals NHS Trust and Hull York Medical School, Anlaby Road, Kingston upon Hull HU3 2JZ, UK

tel. $+44(0) 1482674566$

e-mail sunil.bhandari@hey.nhs.uk

\section{INTRODUCTION}

The completion of a comprehensive clinical clerking is an essential aspect of diagnosis and a fundamental 'job' of a doctor. Learning this role involves learning to make decisions in difficult circumstances, frequently outwith clinical protocols, and learning how to proactively direct and manage patient care.' The Medical Schools Council consensus statement suggests that the role of a doctor (no specific grade) should be 'as a clinical scientist who is able to apply the principles and procedures of medicine to prevent, diagnose, care for and treat patients with illness, disease and injury'.' The most recent Tomorrow's Doctors guidance emphasises the need for doctors to demonstrate their performance and competence in the workplace. ${ }^{2}$

Over the past decade other healthcare professionals have increasingly participated in the delivery of protocolbased healthcare. However, both historically and currently, the characteristic that distinguishes medical practitioners from other staff is their role in clinical diagnosis. With this central duty in mind, anecdotal observations and comments among senior medical staff often suggest that current workplace conditions and training structures leave trainee medical practitioners ill equipped and/or reluctant to make a diagnosis following the medical clerking of acutely ill patients.

While the core of sequential history-taking and examination resulting in a differential diagnosis remains unaltered, in recent times the emphasis on practical repetition (cumulative experience) in reaching reasonable diagnostic conclusions in individual cases has been less clear. ${ }^{3}$ Even modern structured formats such as the Cambridge Calgary methodology emphasise clinical reasoning as an essential part of consultation and communication with patients. ${ }^{4}$ Despite huge advances in structured treatment and confirmatory investigational techniques for many disease processes, a careful and adequate clinical history remains sufficient to lead to a 
diagnostic conclusion in more than $85 \%$ of clinical cases, with the addition of the clinical examination adding another $5-7 \%{ }^{5}$ While physical examination skills are both highly variable and operator dependent, it is important to underline that the process is used to confirm any diagnosis or rule out less likely alternatives. Few acute diagnoses hinge on examination skill alone. The role of experience-related features of initial assessment, such as the overall clinical state 'end of the bed test' (a rough estimate of the severity of a patient's illness), have less clear relevance in reaching a conclusion.

In this study we sought to address the ability of a sample of junior doctors to come to a positive written diagnostic conclusion for acute illnesses on the basis of their initial history and examination.

\section{DESIGN AND METHOD}

This study is a retrospective single-centre audit of case records from patients entering the acute medical assessment unit (AMU), having been seen in the accident and emergency department (A\&E) by a sample of junior doctors, with grades ranging from first year (foundation year, FYI) to fifth year (specialist registrar, ST3). The individual doctor's recorded differential diagnosis was noted (if one had been written) and compared with that eventually defined by the admitting medical consultant. The definition of a 'reasonable differential diagnosis' for the purpose of this audit was taken as a list of possible diagnoses that could be construed by the investigator from the written history, examination and observations provided in the medical notes or subsequently documented by the clinical consultant, acknowledging that not all information from the patient may have been documented.

\section{Data collection}

Data were collected on patient demographics (age and gender) and the grade of the doctor who clerked patients in two settings, A\&E and AMU. All notes were reviewed to establish the final clinical admission diagnosis documented on the emergency form and subsequent AMU form by the relevant junior doctors. The final clinical diagnosis was taken as that defined by the admitting consultant (also recorded on the AMU immediate discharge letter). In the case of transfer to a medical ward, the diagnosis made on final discharge as documented in the discharge letter was used as the comparator. Only patients in hospital for less than three days were selected as it was generally easier to track them and obtain their relevant information.

After data collection the final conclusions of the clinician in A\&E and his or her grade were noted and compared with the data in the summary from the AMU clinicians, with the final diagnosis as a reference.

Patients were grouped into ten specialty areas (Table I) to simplify an analysis of diagnostic activity. This was an
TABLE I Specialty areas of patient grouping

\begin{tabular}{|l|}
\hline Cardiac \\
\hline Endocrine \\
\hline Gastroenterology/hepatology \\
\hline Neurology \\
\hline Non-specific/psychiatry \\
\hline Nephrology \\
\hline Respiratory \\
\hline Rheumatology/bone disease \\
\hline Dermatology \\
\hline Toxicology/poisons \\
\hline
\end{tabular}

arbitrary split based on the most common clinical presentations encountered in acute medicine. This categorisation was carried out based on the symptomatology relating to the relevant system: for example, palpitations would be categorised as cardiac and shortness of breath as respiratory if further supporting symptoms of a respiratory nature (e.g. sputum production) were present. If the shortness of breath was associated with symptoms and signs of acute heart failure (of whatever cause) then a cardiac aetiology was assigned. This aetiological classification could lead to attribution errors, but was in this case with reference to the eventual consultant-based assessment standard.

\section{Statistics}

Data represented in the categories are tabulated as means/medians and ranges where appropriate, or as percentages. Observational comparisons have been made and non-parametric analysis of the data performed using Mann-Whitney $U$ test. A p value of less than 0.05 was taken as significant. Relationships between grades of doctor (expressed as a percentage to normalise for numbers) and the variables of documentation of a symptom and a correct diagnosis were analysed using Pearson product-moment correlations and $r$ values obtained.

\section{RESULTS}

One hundred admissions ( 66 male and 34 female, mean age 57.4 years [range 20-94 years]) were analysed. Most cases were categorised in the cardiac and neurology aetiology domains. The most common cardiac diagnoses were an acute coronary syndrome (or non-ST elevation myocardial infarction). In the neurology domain, the most common diagnosis was epileptic seizure in patients with known epilepsy. The non-specific category consisted of diagnoses such as anxiety disorder, vasovagal episodes, musculoskeletal pain, medication-induced side effects and post-viral syndrome.

In the A\&E setting, 53 cases (53\%) seen by junior $A \& E$ clinicians were given a 'symptom' as their diagnosis or 
TABLE 2 Accident and Emergency diagnostic conclusions

\begin{tabular}{|l|l|l|l|l|}
\hline $\begin{array}{l}\text { Specialty } \\
\text { domain }\end{array}$ & $\begin{array}{l}\text { No. of } \\
\text { patients }\end{array}$ & $\begin{array}{l}\text { Symptom } \\
\text { only or no } \\
\text { diagnosis } \\
\text { detailed }\end{array}$ & $\begin{array}{l}\text { Wrong } \\
\text { system }\end{array}$ & $\begin{array}{l}\text { No. with } \\
\text { correct } \\
\text { diagnosis } \\
\text { (\%) }\end{array}$ \\
\hline Cardiac & 16 & 9 & 3 & $2(12.5)$ \\
\hline Endocrine & 3 & $\mathrm{I}$ & $\mathrm{I}$ & $\mathrm{I}(33)$ \\
\hline $\begin{array}{l}\text { Gastro- } \\
\text { enterology/ } \\
\text { hepatology }\end{array}$ & 8 & 5 & 3 & $0(0)$ \\
\hline Neurology & 24 & 13 & 3 & $8(30)$ \\
\hline $\begin{array}{l}\text { Non-specific/ } \\
\text { psychiatry }\end{array}$ & 17 & $1 \mathrm{I}$ & 4 & $\mathrm{I}(5.8)$ \\
\hline Nephrology & 10 & 6 & 2 & $2(20)$ \\
\hline Respiratory & 7 & 2 & $\mathrm{I}$ & $2(28.6)$ \\
\hline $\begin{array}{l}\text { Rheuma- } \\
\text { tology/ } \\
\text { bone disease }\end{array}$ & 6 & 3 & $\mathrm{I}$ & $\mathrm{I}(16.7)$ \\
\hline Dermatology & 2 & 0 & 0 & $2(100)$ \\
\hline $\begin{array}{l}\text { Toxicology/ } \\
\text { poisons }\end{array}$ & 7 & 3 & 0 & $3(42.9)$ \\
\hline Total & 100 & 53 & 18 & $22(22)$ \\
\hline
\end{tabular}

Note: Numbers do not add up to 100 as in seven cases the conclusions detailed the correct specialty system but had the wrong diagnosis and are not recorded above.

TABLE 3 Acute Medical Assessment Unit diagnostic conclusions

\begin{tabular}{|c|c|c|c|c|}
\hline $\begin{array}{l}\text { Specialty } \\
\text { domain }\end{array}$ & $\begin{array}{l}\text { No. of } \\
\text { patients }\end{array}$ & $\begin{array}{l}\text { Symptom } \\
\text { only }\end{array}$ & $\begin{array}{l}\text { Wrong } \\
\text { system }\end{array}$ & $\begin{array}{l}\text { No. with } \\
\text { correct } \\
\text { diagnosis } \\
\text { (\%) }\end{array}$ \\
\hline Cardiac & 16 & 3 & I & $6(37.5)$ \\
\hline Endocrine & 3 & 0 & 0 & $3(100)$ \\
\hline $\begin{array}{l}\text { Gastro- } \\
\text { enterology/ } \\
\text { hepatology }\end{array}$ & 8 & 2 & 1 & $4(50)$ \\
\hline Neurology & 24 & 5 & 2 & $13(54)$ \\
\hline $\begin{array}{l}\text { Non-specific/ } \\
\text { psychiatry }\end{array}$ & 17 & 7 & 2 & 2 (II.7) \\
\hline Nephrology & 10 & 1 & 2 & $3(30)$ \\
\hline Respiratory & 7 & 0 & I & $5(7 I)$ \\
\hline $\begin{array}{l}\text { Rheuma- } \\
\text { tology/bone } \\
\text { disease }\end{array}$ & 6 & 1 & 1 & $2(28.6)$ \\
\hline Dermatology & 2 & 0 & 0 & $2(100)$ \\
\hline $\begin{array}{l}\text { Toxicology/ } \\
\text { poisons }\end{array}$ & 7 & 1 & 1 & 5 (7I.4) \\
\hline Total & 100 & 20 & 11 & $45(45)$ \\
\hline
\end{tabular}

Note: Numbers do not add up to 100 as in 24 cases the conclusions detailed the correct specialty system but had the wrong diagnosis and are not recorded above. differential diagnosis (Table 2). These consisted of terms such as 'chest pain', 'collapse', 'off-legs', 'haematemesis', 'headache' or 'confusion', and in a proportion of cases had no documented diagnosis. In $18 \%$ of cases the A\&E assessment implied a different domain from the eventual diagnosis; for example, a diagnosis of 'chest infection' when the eventual diagnosis was pulmonary oedema due to ischaemic heart disease. The junior A\&E diagnosis was concordant with the eventual consultant diagnosis in $22 \%$ of cases.

In the sample from the AMU setting, the junior doctors who saw the patients included one relatively experienced ST3 who saw 18 cases. Here 20 cases (20\%) were given a clinical 'symptom' as a diagnosis, and in II (II\%) the wrong domain was given; $45 \%$ (45 cases) of junior doctor diagnoses showed concordance with senior opinion (including nine of the 18 cases seen by the ST3grade doctor).

Examining the grade of the doctor who saw the patients in A\&E revealed a diagnostic weak trend towards greater concordance with increasing grade (Figure I). However, symptom-based assessment was given in more than $50 \%$ of cases in each grade of seniority except ST3 (15\%). Less experienced doctors were more likely to record a symptom when making their diagnostic conclusion. In the AMU setting, there was a trend towards improvement from $\mathrm{FYI}$ to ST3 in documenting a correct diagnosis (Figure 2), while less experienced doctors were again more likely to record a symptom when making a diagnostic conclusion. The overall trend for a correct diagnosis correlated with seniority (Figure 3; $r=0.9$, $p=0.039$ ). However, the overall percentage attempting to document diagnoses remained surprisingly low.

Comparing A\&E to AMU junior doctors indicated that leaving a symptom documented as the final 'diagnostic' conclusion was more common in the A\&E setting (median 50 vs $20.6 \%$; $=0.047$ ). There was no statistical difference in documenting a correct diagnosis but a clear trend to this being better in the AMU setting (median I 7.7 vs $44.4 \%$; $p=0.072$ ).

Examining the background training of clinicians involved revealed two graduates from non-UK medical schools in A\&E. Of these two clinicians, one, an FY2, was from the EU and the other, a final-year core trainee (CT3), was from a non-EU medical university. In the AMU there were three graduates from non-UK medical schools, all were from EU countries. A comparison of performance between these groups and local UK graduates (or the performance of UK graduates from different undergraduate programmes) was not feasible. 


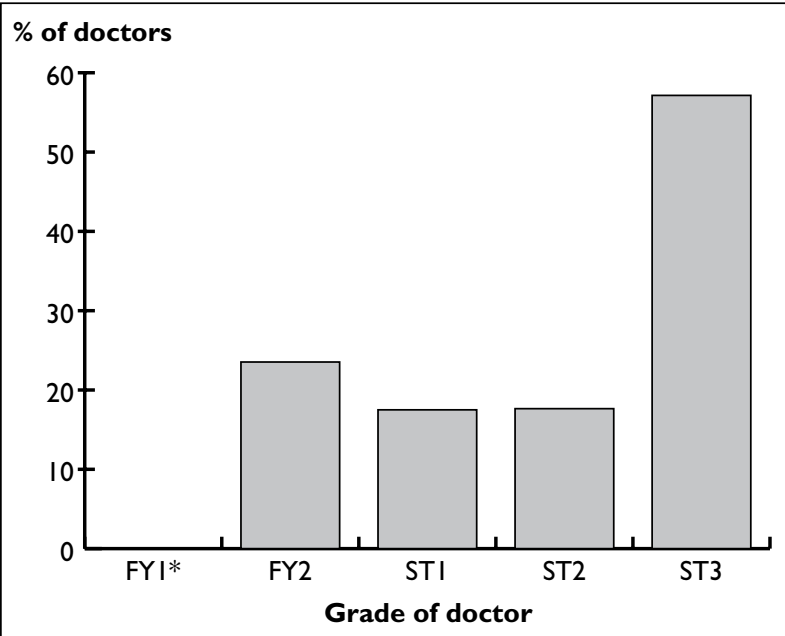

*For FYI there were only two cases seen and therefore the data were not interpretable.

FIGURE I Percentage of Accident and Emergency doctors with a correct diagnosis by grade.

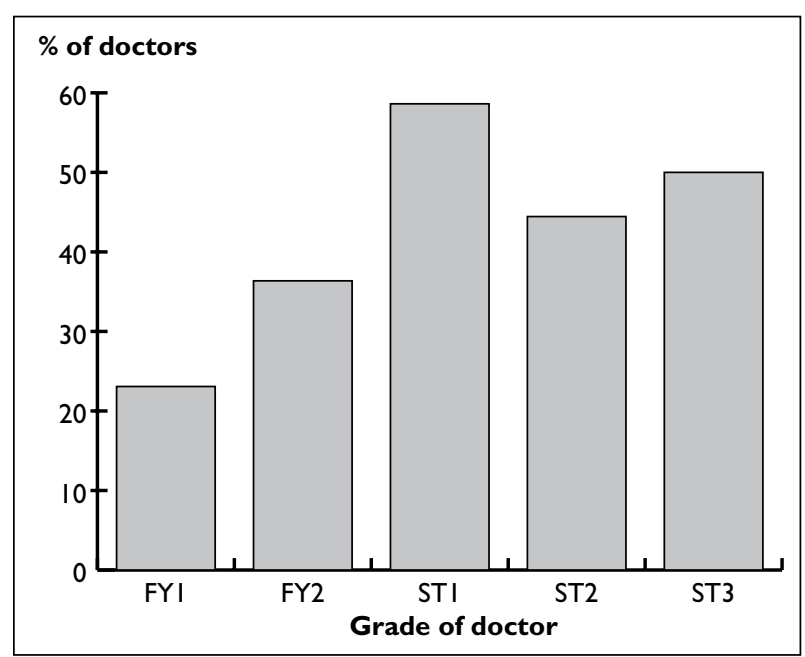

FIGURE 2 Percentage of Acute Medical Assessment Unit doctors with a correct diagnosis by grade.

$\%$ with correct

diagnosis

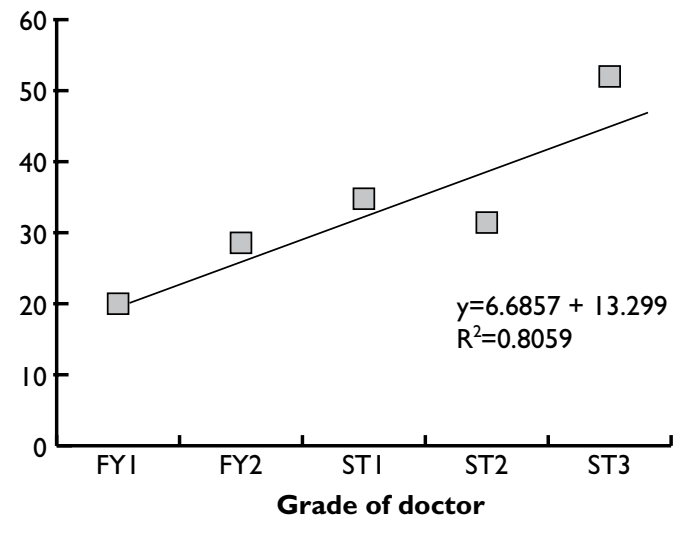

FIGURE 3 Relationship of grade and correct diagnosis in both Accident and Emergency and the Acute Medical Assessment Unit.

\section{DISCUSSION}

This study has obvious limitations. It is a single-centre audit based on an unselected case mix of patients and junior doctors. An ideal sample should include a broad diversity of cases and, perhaps, a wider range of medical staff to avoid bias. ${ }^{6}$ The issue of variable educational standards and teaching structures has been referred to above and cannot be neglected. I chose to fix the population sampled to provide a broad range of pilot information covering a variety of clinical specialties and grades. This sample is certainly representative of the average UK junior doctor while acknowledging the limited generalisability.

The mix of graduate backgrounds in undergraduate training could affect the ability of junior doctors to demonstrate clinical reasoning in practice. Several studies have demonstrated notable differences in outcomes from UK medical schools in terms of postgraduate examination success: ${ }^{7,8}$ however, this is not necessarily representative of 'on the job' clinical diagnostic activity. All UK medical schools stress the need for core medical knowledge in order to reach a reasonable differential diagnosis. None teach or encourage the repetition of a symptom as a final diagnostic conclusion. As the numbers of non-UK graduates involved was small and the spectrum of undergraduate schools involved was not broad I do not regard this as a relevant factor affecting the findings here. They may be relevant in the broader context.

The reference standard used here was based on the supervising consultant opinion or discharge diagnosis. Clearly these are not absolute. Post-mortem/autopsy data reveal average diagnostic error rates of between 10-20\% across the range of hospital assessments. ${ }^{9}$ The comparison here is not simply to the accuracy of the final clinical diagnosis by this grade of staff but more acutely the documented attempt at diagnosis. Clearly the setting of A\&E may disadvantage these clinicians (hostile work environment, inappropriate administrative pressures) and might give some prior cumulative information to AMU juniors. In addition, stepwise information and investigations may affect the ease of diagnosis.

Documentation is another variable. When junior clinicians write down a symptomatic conclusion is this simply as far as they can go in the diagnostic process or are they simply unwilling to commit themselves at that time? What is written might not reflect their level of understanding or diagnostic ability so much as simple lack of confidence. It is important to recognise that there is no accepted standard of practice in this area. It is unclear what percentage of attempted diagnoses could be viewed as appropriate for doctors in training using a consultant opinion as a comparator. Neither is it acceptable to simply ignore this lack of diagnostic 
TABLE 4 How do we become better diagnosticians?

\begin{tabular}{|l|}
\hline Observe and question others who make diagnoses \\
\hline Practise making clinical diagnoses more often \\
\hline $\begin{array}{l}\text { Be formally taught how to diagnose using various reasoning } \\
\text { strategies }\end{array}$ \\
\hline $\begin{array}{l}\text { Establish more continuity of care of patients for junior doctors } \\
\text { to allow them to follow patients through to final discharge }\end{array}$ \\
\hline $\begin{array}{l}\text { Allow for time and exposure to a variety of clinical cases - } \\
\text { 'on the job' experience }\end{array}$ \\
\hline
\end{tabular}

activity given the huge investment placed in medical education where making a diagnosis is at the core.

This small study presents data on how contemporary junior doctors complete and document fundamental diagnostic assessments in an acute care setting. The results suggest that junior doctors are clearly reluctant to document a provisional differential diagnosis based on their history and examination despite programmed training and irrespective of its defined accuracy. Diagnostic effort and relative accuracy improved with grade of doctor (experience, time in service) but clearly might be regarded as suboptimal. The natural standard would obviously be a $100 \%$ attempt rate. The recording of symptom-based 'diagnosis' remains worryingly high among junior clinicians in all areas and at all grades. In $A \& E$, irrespective of grade, the use of a clinical 'symptom' overall was more prevalent than in AMU $(p=0.047)$.

It is not clear whether juniors or patients perceive clinical reasoning and diagnosis as an important part of the consultation/communication process. It is likely that more senior clinical staff, whether medical or nursing, do recognise this activity among juniors as key. One might expect medical trainees to realise that once a correct diagnosis or differential diagnosis has been defined the institution of treatments can become straightforward. Protocol-based treatment can, in many situations, be administered by any competent healthcare professional, often more reliably than by junior doctors. It seems a concern that decision-making and clinical reasoning in reaching a diagnosis is so poorly executed by junior doctors in this sample. Clearly this impairs the delivery of any possible treatment, however administered.

The origins of this might relate to uncertainties within the minds of individual junior doctors, fearing an incorrect diagnosis. Clearly the purpose of consultation is to reach the most likely clinical diagnosis and a differential diagnosis of less likely possibilities in view of the variances in patients' histories. Only then can a clinician establish the relevant tests required to confirm the correct diagnosis and exclude the others. The process of clinical reasoning was not apparent.
There was a positive correlation between grade from FYI to ST3 in reaching a diagnosis $(r=0.9)$ but less in reaching symptomatic diagnoses. The induction of junior doctors in our A\&E is aimed at allowing junior doctors to construct a diagnosis and management plan which is, when possible and feasible, assessed by the senior A\&E clinicians (using case-based discussions and observations, which are challenging in such a busy environment). One might expect A\&E clinicians to adopt a probabilistic approach to diagnosis (Murtagh's process). Murtagh's process is where junior doctors learn the most common causes for a particular presenting complaint and a list of differential and sometimes serious diagnoses which need to be considered and excluded by individualised assessment. ${ }^{10}$ This process helps to reduce clinical error but appears lacking in our sample." This is even less likely where many junior doctors did not document any diagnosis and $53 \%$ simply reiterated a 'symptom'.

Where diagnosis lay in a non-specific domain, attempts at possible diagnoses rates were particularly poor. Sixtyfive per cent listed symptomatic presentation in A\&E and $41 \%$ in AMU. Plausible alternative diagnoses were not entertained with a provisional diagnosis. ${ }^{12}$ This lack of clinical reasoning may be due to the increased uncertainties and perhaps complexity of the cases in this category.

One contemporary problem that might be relevant to a deficiency in diagnostic skill could be the lack of continuity of patient care. This encourages deferred judgement, and trainees often do not see the outcomes of their actions (or inactions). Direct feedback from consultants cannot be given if the admitting clinician is simply absent through enforced working patterns. Absence on post-take ward rounds and failure to present cases to admitting consultant staff is now sadly routine in UK hospitals.

\section{IMPROVING DIAGNOSTIC STANDARDS}

Increased clinical practice in diagnosis and the insistence of documenting conclusions is critical to improvement (Table 4). Gaining experience takes time, and minimal standards must be defined and implemented in the process of clinical diagnosis. Work patterns that encourage deferred diagnoses, poor/non-existent conclusions and a lack of feedback should be amended as a training priority.

Experts and novices see things differently and there are many relevant theories of decision-making. ${ }^{13,14}$ The greatest hurdle in making judgements in the face of uncertainty is the role of intuition within this framework in a way that is not biased. Judgements may also be influenced by views of risk and whether junior doctors are taught or encouraged to be particularly risk averse. We need to teach doctors to frame their individual written diagnosis in every case based on probability and to avoid undue 
assumption. Perhaps a simple, logical approach with feedback, incorporating structured reasoning and remedial strategies where necessary, may suffice. ${ }^{15}$

Developing expertise and experience through repetition allows the acquisition of reasoning strategies. ${ }^{16-18}$ Locally, a more intensive consultant-led service facilitates more direct assessment and feedback during history-taking and examination by junior doctors, but alternatively it can also encourage inappropriate deferred activity and judgements. More importantly, there must be a clear emphasis on moving away from documenting or reiterating symptoms as the conclusion of clerking.

\section{REFERENCES}

I Chief Medical Officers of England, Scotland, Wales and N Ireland, Academy of Medical Royal Colleges, Association of UK University Hospitals, BMA, COPMeD, GMC, The King's Fund, Medical Schools Council, NHS Employers, PMETB. The consensus statement on the role of the doctor. 2008. Available from: http://www.medschools.ac. uk/AboutUs/Projects/Documents/Role\%20of\%20Doctor\%20 Consensus\%20Statement.pdf

2 General Medical Council. Tomorrow's doctors: recommendations on undergraduate medical education. London: General Medical Council; 2009.

3 Elstein AS, Schwarz A. Clinical problem solving and diagnostic decision making: selective review of the cognitive literature. $B M$ 2002; 324:729-32. doi: 10.1 I36/bmj.324.7339.729

4 Kurtz S, Silverman J, Benson J et al. Marrying content and process in clinical method teaching: enhancing the Calgary-Cambridge Guides. Acad Med 2003; 78:802-9.

5 Hampton JR, Harrison MJ, Mitchell JR et al. Relative contributions of history-taking, physical examination, and laboratory investigation to diagnosis and management of medical outpatients. BMJ 1975 2:486-9. doi: I0.1 I36/bmj.2.5969.486

6 Robson C. Real world research. Oxford: Blackwell; 1993.

7 McManus IC, Elder AT, de Champlain A et al. Graduates of different medical schools show substantial differences in performance in MRCP Partl, Part 2 and PACES examinations. BMC Med 2008; 6:5. doi:10.1I86/174I-7015-6-5

8 Bowhay AR, Watmough SD. An evaluation of the performance in the UK Royal College of Anaesthetists primary examination by UK medical school and gender. BMC Med Educ 2009; 9:38. doi: I0.I I86/I472-6920-9-38

\section{CONCLUSIONS}

This study suggests that poor levels of diagnostic synthesis among junior doctors are commonplace. This is partly related to grade and clinical setting but remains suboptimal even in relatively experienced contemporary trainees regardless of specialty. The structure of postgraduate and undergraduate training must refocus on encouraging documented diagnostic conclusions. Symptom-based diagnoses are unacceptable and should be modified by structured feedback and work patterns adjusted to facilitate personal responsibility for diagnostic conclusions.

9 Shojania KG, Burton EC, McDonald KM et al. Changes in rates of autopsy-detected diagnostic errors over time: a systematic review. JAMA 2003; 289:2849-56. doi:10.1001/jama.289.21.2849

10 Murtagh J. Common problems: a safe diagnostic strategy. Aust Fam Physician 1990; 19:733-42.

II Croskerry P. Cognitive forcing strategies in clinical decision making. Ann Emerg Med 2003; 4I:10-120. doi:10.1067/ mem.2003.22

12 Levy PD, Sherwin RL, Kuhn GJ et al. Clinical diagnostic reasoning. N Engl J Med 2007; 356:I272-4. doi: I0.1056/NEJMc063606

13 Russo JE, Schoemaker PJ. Confident decision making. London: Piatkus; 1989.

14 Goodwin P,Wright G. Decision analysis for management judgement 4th ed. Chichester:Wiley; 2009.

15 Scott I. Errors in clinical reasoning: causes and remedial strategies. BMJ 2009; 339:22-5.

16 Norman G. Building on experience - the development of clinical reasoning. $N$ Engl J Med 2006; 355:225I-2. doi:I0.1056/ NEJMe068I34

17 Bowen JL. Educational strategies to promote clinical diagnostic reasoning. N Engl J Med 2006; 355: 2217-25. doi:10.1056/ NEJMra054782

18 Heneghan C, Glasziou P, Thompson M et al. Diagnostic strategies used in primary care. BMJ 2009; 338:b946. doi:I0.I I36/bmj.b946

\section{EXAM PREPARATION COURSES: Please advise your trainee colleagues}

\section{MRCP PART 2 REVISION COURSE}

\section{4-26 Feb 2010}

- Three-day exam-orientated course covering many aspects of clinical medicine relevant to the Membership Exam

- Fee: $£ 450$

Tel: 0I3। 2473649

Fax: 0131 2204393

E-mail: a.fairbairn@rcpe.ac.uk

\section{MRCPCH REVISION COURSES}

VIDEO COURSES

12 Feb OR 7 June 2010

- Fee: $£ 200$ per course

Tel: 0 I3। 2473607

Fax: 0I3। 2204393

Email: c.gray@rcpe.ac.uk
ETHICS AND COMMUNICATION

SKILLS COURSES

I5-I6 Feb OR 9-10 June 2010

Fee: $£ 300$ per course

Tel: 0I3I 2473607

Fax: 0131 2204393

Email: c.gray@rcpe.ac.uk 